calls for much more than product-servicing contacts between maker and user. The evaluation of any fibre in terms of these properties is a time-consuming process, calling for very close collaboration between all branches of the industry and for some refinement of existing experimental methods. If we understand it correctly, consideration of Mr. White's paper leads to the inevitable conclusion that the textile industry must dictate, in tempo and direction, the textile realization of the products submitted to them by the organic chemist. It is therefore important that, through its own research and development work, the textile industry should be in a position to exert the maximum critical pre-selection of organic chemicals proposed for use as textile fibres.

J. K. Berry described the contributions which rayons, especially high-tenacity regenerated celluloses, are making in engineering fields, and discussions brought out the value of collaboration with, for example, the rubber tyre industry. $\mathrm{He}$ is of the opinion that the expensive high twist required by tyre makers does not necessarily contribute to fatigueresistance, and that there is a possible prejudice about the matter which can only be cleared up by co-operative investigation in both industries.

W. J. Hamburger, director of Fabrics Research Inc., Boston, U.S.A., presented a paper entitled "Industrial Applications of Stress-Strain Relationships". The contents were a sound engineering approach to fine-structure problems. But the author's remarks had to do more with the philosophy of research $\mathrm{He}$ described how a privately owned consulting laboratory not only can afford to have ideals in the prosecution of some fundamental research, but also, in his case, has been able to get industrial clients to pay for it and to discover that it paid them back.

The remaining papers were : the industrial application of sound reduction (N. Fleming) ; solubility number-a measure of cellulose degradation (D. A. Derrett-Smith) ; measuring the swelling of fibres in water (J. M. Preston and M. V. Nimkar); the development of a laundry, washing process (F. C. Harwood and F. R. Hill); University departments their influence on the efficient conduct and utilization of research (H. A. Turner). Messrs. Harwood and Hill revealed how, in the institution of a sound washing technique for laundries, new knowledge was slowly gained and, of necessity, only slowly superimposed on the rule-of-thumb methods of preLaunderers Research Association days. Mr. Turner's paper was the one contribution to formal education of the scientific worker. The Conference was clear on the need for the type of scientific worker who could ensure the transmission of new knowledge to his employers. Mr. Turner considered the way in which he might best be trained, in a university department where technology was properly evaluated and research regarded as a training activity as well as an $e$ d in itself.

The Conference succeeded in revealing many of the obstacles in the way of maximum liaison between research activity and the application of new knowledge. If it were not always made clear how such could be removed, at least the problems involved were clarified, and it now remains for all concerned to contribute towards their solution. In this, through its Transactions, Proceedings and the organisation of specialized conferences, the Textile Institute itself has a unique opportunity of exercising leadership.

JoHN BouLTON

\section{BACTERIAL OXIDATION OF ARSENITE}

\author{
By DR. A. W. TURNER, O.B.E.
}

Scientific and Industrial Research Organisation, Division of Animal Health and Production, Parkville, Victoria

$I^{N}$ 1918 H. H. Green ${ }^{2}$ isolated from arsenical cattledipping fluids in South Africa a bacterium, provisionall referred to as Bacillus arsenoxydans but since/ost ${ }^{2}$, which was able to grow in culture media ch ntaining up to I per cent of $\mathrm{As}_{2} \mathrm{O}_{3}$ as arsenite and to bring about its oxidation to arsenate. In view of the well-known toxicity of tervalent arsenicals, now largely explicable in terms of their inhibitory action upon highly important sulphydryl-dependent metabolic enzymes ${ }^{3,4}$, it is particularly unfortunate that Green's valuable paper, being published in an annual report mainly devoted to veterinary research, apparently escaped the attention of enzymologists and general bacteriologists; for the enzymic mechanism of arsenite oxidation was never studied while the strain was available, nor was the existence of arsenite-oxidizing bacteria ever afterwards reported.

However, during an investigation into spontaneous oxidation of arsenite in cattle-dipping fluids from Queensland, we readily isolated fifteen strains of heterotrophic bacteria which, like Green's bacterium, not only tolerate up to $0 \cdot 1 M$ arsenite, but also bring about its oxidation to arsenate, and we have taken the opportunity to inquire into the mechanism of arsenite oxidation. These bacteria all appear to belong to the genus Pseudomonas; but five distinct types or possibly species can be recognized on the basis of colony characteristics, serological relation. ships, thermal tolerances, pigment production, utilization of carbon sources, and biochemical criteria. One type, found only once, resembles fairly closely the published description of $B$. arsenoxydans.

The enzymic mechanism has been studied mainly with the particularly active strain 17 , belonging to Type 5. In most of the work reported here, arsenite oxidation has been estimated by iodometric titration but in some studies which will be reported later, this has been supplemented and amplified by Warburg respirometry experiments.

Washed cells harvested from suitable liquid media, such as Koser's citrate containing $0.02 M$ sodium arsenite, actively catalyse the oxidation of arsenite to arsenate when aerated. Enzymic activity appears early during growth in arsenite media and is strongly adaptive; non-adapted cells are inactive and develop activity only after a lag-period in the presence of substrate. Activity of washed cells is not dependent upon a source of external phosphate, since it is identical in phosphate or collidine buffers at the same $p \mathrm{H}$. The optimal $p \mathrm{H}$ lies between $6 \cdot 0$ and $6 \cdot 7$, at which arsenite is still almost completely undissociated ( $p K a=9 \cdot 12$ ), and this range is also optimal for growth and arsenite oxidation in arsenite-Koser modium. At the optimal $p \mathrm{H}$, cells aerated optimally can oxidize about $90 \mu M$ arsenite per hour per mgm. dry weight. Oxidation is completely inhibited outside the range $p H$ 3-11. Under the experimental conditions, the optimal temperature for oxidation by aerated cells in phosphate buffer is about $40^{\circ} \mathrm{C}$.; the $Q_{10}$ between $20^{\circ}$ and $30^{\circ}$ is 1.73 , and $Q_{10}$ between $30^{\circ}$ and $40^{\circ}$ is 1.43 ; and between $20^{\circ}$ and $40^{\circ}$ 
Bělahrádek's temperature coefficient $b$ is $1 \cdot 27 \pm 0 \cdot 08$. The critical thermal increment $\mu=7,750 \pm 600 \mathrm{cal}$., which may be compared with the corresponding values for the energy of activation, $E$, associated with inorganic catalytic arsenite oxidation: thus it may be calculated graphically from the data of Reinders and Vles ${ }^{5}$ that with copper, $E=12,400$ cal. between $15^{\circ}$ and $35^{\circ}$, and with acid-washed 'Norit' charcoal, $E=250$ cal. between $0^{\circ}$ and $26^{\circ}$ and 7,000 cal. between $26^{\circ}$ and $35^{\circ}$. Arsenite oxidation is inhibited by cyanide (100 per cent by $0.001 M$ and 50 per cent by $0.00003 M$ ) and by azide; and it is inhibited up to 50 per cent by carbon monoxide $(p \mathrm{CO}=0.95)$ in the dark, the inhibition being partly reversed by light. These characteristics strongly suggest that cytochrome oxidase plays an essential part in arsenite oxidation. This is consistent with the destruction of arsenite-oxidizing activity by desiccation, acetone or toluene. Arsenite oxidation is not inhibited by urethane $(0.1 M)$ or by iodoacetate $(0.01 M$ at $p H$ $5 \cdot 3$ or $6 \cdot 4)$. It is, however, partly inhibited by fluoride (21 per cent by $0.01 M, 67$ per cent by $0 \cdot 1 M$ ) and by pyrophosphate ( 16 per cent by $0.02 M)$, suggesting the participation of certain divalent metallic ions, although it is not inhibited by diethyldithiocarbamate $(0 \cdot 001 M)$ or by $\alpha, \alpha^{\prime}$-dipyridyl $(0 \cdot 001 M)$.

By means of the anaerobic Thunberg technique, evidence is readily obtained that adapted cells, but not unadapted cells, contain an arsenite 'dehydrogenase'. By grinding cells with glass and submitting to a high gravitational field, the enzyme is obtained in a soluble form, together with traces of a substance (presumably bacterial cytochrome c) having an absorption maximum at $\lambda=552 \mathrm{~m} \mu$ after reduction by dithionite. Unlike cell suspensions, this cell-free clear material has no measurable arsenite-oxidizing activity when aerated.

In order to demonstrate arsenite-dehydrogenase activity, it is necessary to use, as electron acceptors, redox indicators with $E_{0}$ values approximately higher than that of the arsenite-arsenate system itself $\left(E_{0}^{\prime}\right.$ at $p H \quad 7 \cdot 0=+0 \cdot 077 \mathrm{~V}$. to $+0 \cdot 167 \mathrm{~V}$., depending upon which of the several values for $E_{0}$ recorded in the literature is accepted). Suitable acceptors are indophenol-2:6-dichlorophenol, phenol blue, and $m$-carboxy-phenol-indo-2: 6-dibromophenol $\left(E_{0}^{\prime}\right.$ at $p H$. $7 \cdot 0=+0 \cdot 217 \mathrm{~V} .,+0 \cdot 224 \mathrm{~V}$. and +0.250 V. respectively). With indophenol-2:6dichlorophenol, arsenite dehydrogenase has an optimum around $p \mathrm{H} 4 \cdot 5$.

The $E_{0}$ values are known for the manmalian cytochromes $^{6,7}$; thus, at $p H \mathrm{H} \cdot 0, E_{0}{ }^{\prime}$ for cytochrome $b=-0.04 \mathrm{~V}$., for $c=+0.262 \mathrm{~V}$. and for $a=$ $+0 \cdot 29 \mathrm{~V}$. It is therefore clear that, unless the values for the corresponding bacterial cytochromes differ greatly from these, the cytochromes involved in bacterial oxidation of arsenite could include $c$ as well as $a$, but could not include $b$. In this connexion it is significant that the soluble dehydrogenase preparation rapidly eatalyses the reduction by arsenite of mammalian ferricytochrome $c$ and also of any unreduced bacterial cytochrome $c$ in the dehydrogenase preparation itself, the reactions occurring aerobically since ferrocytochrome $c$ is not autoxidizable in air. The possibility that unrecognized electron-transporting mechanisms are required between arsenite dehydrogenase and cytochrome $c$ cannot be excluded; but they would have to possess redox potentials intermediate between those of the arsenite-arsenate system and the ferri-ferrocyto- chrome $c$ system, and therefore would not resemble any at present known to be concerned in cellular oxidations, with the possible exception of Slater's ${ }^{8}$ 'factor', of unknown $E_{0}$, which operates between cytochromes $b$ and $c$.

The mechanism of bacterial oxidation of arsenite therefore appears to comprise the coupling of an adaptive arsenite dehydrogenase system with the cytochrome system; the two electrons which are generated according to the standard oxidation. reduction equation

$$
\mathrm{H}_{3} \mathrm{AsO}_{3}+\mathrm{H}_{2} \mathrm{O} \rightleftharpoons \mathrm{H}_{3} \mathrm{AsO}_{4}+2 \mathrm{H}^{+}+2 \varepsilon^{-}
$$

are probably transferred through cytochrome $c$ to cytochrome $a$ and thence to atmospheric oxygen via cytochrome oxidase, water being regenerated with the aid of the associated two protons. There is no evidence that these bacteria can utilize the energy of oxidation of arsenite for growth either autotrophically or heterotrophically ; indeed, the presence of $0.02 M$ arsenite in Koser's medium makes little difference to the growth-rate. It is therefore possible that the arsenite-oxidizing enzyme complex has been evolved as a protective mechanism.

The above investigation will be reported in greater detail elsewhere; meanwhile, a fuller investigation of the enzymic mechanism, including a study of the cell-free soluble arsenite dehydrogenase, is being continued.

${ }^{1}$ Green, H. H., Rep. Dir. Vet. Res. S. Afr., 5-6, 593 (1918).

${ }^{2}$ du Toit, P. J., personal communication (1947).

${ }^{3}$ Barron, E. S. G., and Singer, T. P., J. Biol. Chem., 157, 221 (1945). ${ }^{4}$ Singer, T. P., and Barron, E. S. G., J. Biol. Chem., 157, 241 (1945).

${ }^{5}$ Reinders, W., and Vles, S. I., Rec. Trav. Chim. Pays-Bas, 44, 29 (1925). ${ }^{6}$ Stotz, E., Sidwell, A. E., and Hogness, T. R., J. Biol. Chem., 124,

' Ball, E. G., Biochem. Z., 295, 262 (1938).

${ }^{8}$ Slater, E. C., Nature, 161, 405 (1948).

\section{$18 / 2$ \\ ROTHAMSTED EXPERIMENTAL STATION}

\section{REPORT FOR 1947}

$\mathrm{W}_{\mathrm{I}}^{\mathrm{H}}$ HEN reading th g fol report on Rothamsted Experimental ston for 1947, it is impossible not to be impressod by the ever-widening scope of agriculturalf esparch. When Rothamsted was founded, more the chtury ago, most of the problems awaiting solpton by the few agricultural scientists-mostly chemifts-must have appeared within reasonable distance of solution. Indeed, the well-planned experiments laid down by Lawes and Gilbert soon brought results of inestimable value to farming at home and abroad. As work proceeded, however, deeper problems appeared on the horizon, and the limitations of many of the ordinary kinds of field experiments and routine analyses became obvious. Agriculture is the meeting ground of many sciences, and it became necessary not only to split it up into its component applied sciences, but also to enlist the aid of workers in pure science.

This volume includes fifteen departmental reports : chemistry, physics, microbiology, pedology, botany, crop physiology, statistics, plant pathology, biochemistry, entomology, bees, insecticides and fungicides, field experiments, the farms, and Woburn. The work at Rothamsted, as in the past, is directed 